\title{
Arbuscular mycorrhizal symbiosis as sustainable alternative in the Stevia rebaudiana Bertoni production
}

\author{
Cauich-Cauich, Rodrigo Armando ${ }^{1}$; Tun-Suárez, José María ${ }^{1}$; Herrera-Parra, \\ Elizabeth de los Ángeles ${ }^{2}$; Cristóbal-Alejo, Jairo ${ }^{1}$; Lozano-Contreras, Mónica Guadalupe ${ }^{2 *}$ \\ 1 Tecnológico Nacional de México/División de Estudios de Posgrado e Investigación/ Instituto Tecnológico de \\ Conkal, Avenida Tecnológico s/n, Conkal, Yucatán, CP. 97345. \\ 2 Campo Experimental Mocochá, Instituto Nacional de Investigaciones Forestales Agrícolas y Pecuarias, \\ Antigua carretera Mérida-Motul Km. 24.5, Mocochá, Yucatán, México, C.P. 97454. \\ * Correspondence: morbica@gmail.com
}

\begin{abstract}
Objective: Stevia rebaudiana Bertoni is a crop that can meet the demand for natural sweeteners; however, this demand requires a sustainable production, as a result of the inclusion of its steviol glycosides or active ingredients in the food and pharmaceutical industries.

Design/methodology/approach: Modern agriculture implies the integrated use of valid natural resources, such as the arbuscular mycorrhizal fungi (AMF). These microorganisms establish a symbiotic relationship with, at least, $80 \%$ of the plants, to which they provide multiple benefits. They can directly and indirectly improve crop productivity, through nutrient (particularly, phosphorus) translocation of the soil solution.

Results: As a sustainable alternative for the production of $S$. rebaudiana, they improve its nutritional state, resulting in a higher biomass production and glycoside concentration - fundamental yield parameters. Additionally, they promote resistance to biotic and abiotic stress factors and improve soil quality.

Limitations/implications: It is worth mentioning that this fungi-plant mutualism is approximately 400 million years-old; however, it has only aroused interest during the last few years.

Findings/conclusions: Although arbuscular mycorrhizal fungi (AMF) are an exploitable resource, their communities are threatened by biotic factors — such as the interaction with other microorganisms - and abiotic factors - which involve bad agricultural practices.
\end{abstract}

Keywords: mycorrhizae; sustainability, Stevia, biomass, glycosides.

Gitation: Cauich-Cauich, R. A., Tun-Suárez, J. M., Herrera-Parra, E. de los Á., Cristóbal-Alejo, J., \& Lozano-Contreras, M. G. (2022). Arbuscular mycorrhizal symbiosis as sustainable alternative in the Stevia rebaudiana Bertoni production. Agro Productividad. https://doi.org/10.32854/ agrop.v15il.2093

Editor in Chief: Dr. Jorge Cadena Iñiguez

Received: July 20, 2021. Accepted: January 3, 2022. Published on-line: January, 2022.

This work is licensed under a Creative Commons Attribution-NonCommercial 4.0 International license.

\section{INTRODUCTION}

Crop phytosanitary and nutrient management is usually based on the use of agrochemicals, with the aim of achieving a maximum exploitation of the crop's productivity; this practice requires knowledge about the agricultural needs of the plant species. However, the irrational use of these products creates problems in the agricultural sector, such as pollution, soil infertility, salinity, pest resistance, etc. (Amekawa, 2009). Sustainability is the new development trend for food production. Modern agriculture is adopting biotechnical feasible tools to achieve a sustainable production, through the application of beneficial microorganisms, both for the plant and for the soil. These

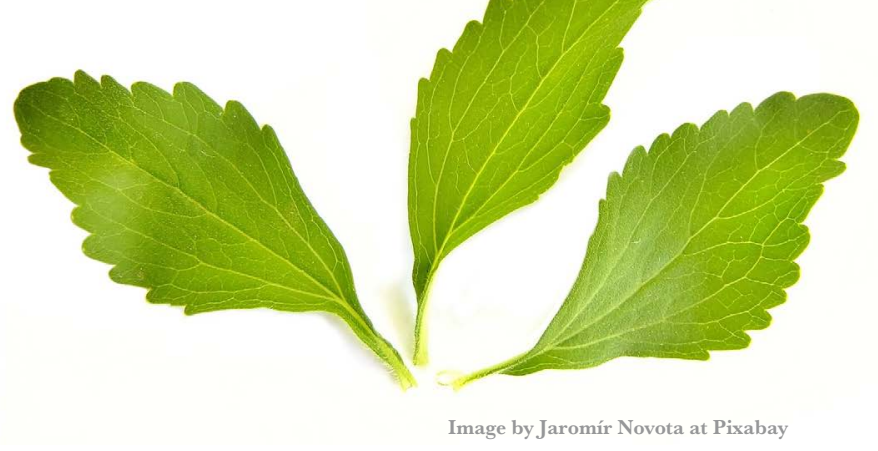


microorganisms have similar effects than agrochemicals and can replace them or reduce their use (Jeffries et al., 2003).

Soil microorganisms are an important ingredient; some groups are more studied than others, as a result of the benefits they provide to crops. This review highlights the multiple benefits that arbuscular mycorrhizal fungi (AMF) - considered a feasible alternative for sustainable agriculture- provide to plants.

Mutualistic symbiotic relationships are 400-million-year-old (Bonfante and Genre, 2008). Currently, the AMF establish symbiosis with at least $80 \%$ of the plant species (Vierheilig, 2004). However, in an evolutionary context, plants evolved with the help of arbuscular mycorrhizae relationships (Simon et al., 1993), as a result of a most interesting peculiarity of the AMF: they are forced symbionts, i.e., they need a host or phytosymbiont to survive and they require a compatible relationship that provides a mutual benefit (Harrison, 1997).

During the last few years, the successful inoculation of plants of agricultural interest with AMF has been proved to promote growth and enhance the yield of the plant, as a result of an improvement in nutrient absorption.

This positive effect has also been achieved in Stevia rebaudiana Bertoni (Giovannini et al., 2020; Tavarini et al., 2018; Mandal et al., 2013). This plant was introduced to Mexico mainly as a consequence of the demand for natural sweeteners, which diabetics can consume; they also replace synthetic sweeteners which cause health problems. Additionally, after its approval as food sweetener in several countries, Stevia rebaudiana Bertoni has acquired a high exportation potential. Its intense sweetness and medicinal properties have made it a topic of scientific and commercial interest. The importance of $S$. rebaudiana is also based on the fact that its leaves have a zero-calorie compound that is over 300 times sweeter than sucrose. This compound is made up of steviol glycosides (SG) (stevioside, steviolbioside, rebaudioside-A, B, C, D, and dulcoside-A) (Tavarini et al., 2015), which are biosynthesized in a chain reaction from the pyruvate and the glyceraldehyde 3-phosphate (Brandle and Telmer, 2007; Mandal et al., 2015). Among these glycosides that can be found in the leaves of the plant — which makes the leaves sweet-, stevioside and rebaudioside-A make up the highest proportion (80\%).

The leaves of $S$. rebaudiana have a great proportion of its SG content; therefore, its production is mainly focused in the amount of biomass and SG content.

In this context, the main benefit of the AMF is phosphorus translocation, a key element in the SG biosynthesis. Most researches have focused on the improvement of those two important parameters. Mandal et al. (2013) evaluated the effect of Rhizophagus fasciculatus (Thaxt) on yield and SG concentration. The interaction improved the biomass and the stevioside and rebaudioside-A concentration. Tavarini et al. (2018) used $R$. irregulare to modify the growth habit of the plants, obtaining more branches and less height; they also reported an $88 \%$ colonization. This confirmed the susceptibility of the plants to symbiosis and AMF colonization. Vafadar et al. (2014) also showed that AMF inoculation efficiently increases the dry weight of the leaves of $S$. rebaudiana, using relatively low doses of chemical fertilization. 
The positive effects of AMF in agriculture have been widely described; they promise an eco-friendly production. The information about the mechanisms that participate in the multiple benefits that the AMF provide to plants must increase. Most of these benefits have been attributed to the improvement of nutrient uptake by the roots. The objective of this review was to discuss the benefits and mechanisms that participate in the arbuscular mycorrhizal symbiosis for the improvement of the biomass and the metabolite of the $S$. rebaudiana crop, as well as the factors that limit the AMF use.

\section{Stevia rebaudiana productive potential}

Stevia has several phytochemical characteristics which makes it a crop of interest for the food industry - as sweetener, antioxidant, and dietary supplement - and for the pharmaceutical industry - for the treatment of diabetes mellitus, since it does not produce a glycaemic response. The leaves of $S$. rebaudiana can achieve a zero-calorie natural sweetness higher than sucrose (Ramesh and Megeji, 2006); they have a unique composition in the presence of labdane, phenolic acids, sterols, triterpenoid, chlorophyll, organic acids, monosaccharide, and disaccharide (Gardana et al., 2010; Tavarini and Angelini, 2013).

In mid-December 2008, the Food and Drugs Administration (FDA) established that the components of $S$. rebaudiana were safe for human consumption. The same year, the JECFA/ FAO (experts on food additives) agreed with the FDA's approval of S. rebaudiana for human consumption. In 2010, the JECFA, along with the World Health Organization, awarded the plant the safe food certification.

Since then, it has been considered a crop with high economic potential and, currently, it is considered the second sweetener worldwide. China is the main commercialization point: $50 \%$ of the production is sold in its own domestic market. China also provides at least $75 \%$ of the world production and its main exportation routes are Japan and the USA (Sarmiento-López et al., 2021). Paraguay is the second producer of S. rebaudiana (Mogra and Dashora, 2009). Its market is focused in dry leaves commercialization, mainly supplying the EU, which has a sweetener annual consumption of ten thousand tons. Therefore, the demand of $S$. rebaudiana provides an opportunity for Mexican farmers seeking to generate a profitable crop with exportation potential.

\section{Arbuscular mycorrhizae}

Mycorrhizae imply mutualism between the arbuscular mycorrhizal fungi (AMF) and the plant. Its name comes from the Greek terms "mikos" (fungi) and "rhiza" (root). It literary means "fungi root". Specifically, it belongs to the "endomycorrhizae" type and it is the most abundant group in horticulture. This kind of fungi belong to the Glomeromycota division and are forced symbionts. The AMF have different particular structures such as hyphae, vesicles, and arbuscules. The hypahe are main structures and can be classified as "ineffective" - those that initiate the colonization and establish contact with the roots-, "absorbent" - those that explore the soil and exchange nutrients-, and "fertile" - those in charge of the asexual production of spores (Camarena-Gutiérrez, 2012).

Glomeromycota is made up of nine families (Acaulosporaceae, Archaeosporaceae, Diversisporaceae, Enthrophosporaceae, Glomeraceae, Gigasporaceae, Geosiphonaceae, 
Pacisporaceae, Paraglomeraceae) and at least 200 species have been described so far (Schüßler et al., 2001). They are characterized by the intracellular and intercellular growth of the cortical cells of the root; they show an internal development of arbuscules (dichotomously-divided hypae, invaginated by the plasma membrane of the cortical cells, and they have short life periods) and vesicles (lipid bodies that are created in the terminal part of the hyphae) (Brundrett, 2004; Rich et al., 2014).

The arbuscular mycorrhizal symbiosis takes place when an AMF spore germinates and branches in all directions, in order to find and establish contact with the roots of the plant. In this first "presymbiosis" stage, the receptive signs of the plant (flavonoids and elicitors) identify and recognize the symbiont (Harrison, 1997). However, the amount of enzymes, catalases, and peroxidases also increases; this process occurs at the same time that the appresorium (initial symbiotic structure) appears and the fungi penetrates the root. The biochemical communication between the two mutualists does not allow the plant to reject or defend itself from the fungi; this communication produces morphogenetic changes that are crucial to initiate the colonization of the roots and to guarantee mutual benefits (Akiyama, 2005).

\section{Advantages of the arbuscular mycorrhizal symbiosis in Stevia rebaudiana}

The symbiosis benefits for cultivated plants have been reported in survival, morphological, and productive terms. AMF are known to be capable of improving the physiological conditions of plants, even in difficult conditions, such as soil tension caused by heavy metals (Rillig, 2004), soil compaction, salinity, and drought (Miransari et al., 2007). Additionally, an improvement in growth and productivity of the cultivated plants has been reported. The AMF diversity in the soil is very important, because they have a differential effect in the host (Kernaghan, 2005). Although $S$. rebaudiana is highly susceptible to AMF colonization, studies about the effects of mycorrhizal symbiosis on its quantitative and qualitative production are still limited (Giovannini et al., 2020; Mandal et al., 2015).

Most researches focus on the improvement of mineral nutrition: the main benefit that the AMF provides to mycorrhizae plants. However, this benefit also unchains an increase in the chlorophyl concentrations which, on their turn, modify the photosynthetic rate, resulting in a higher physiological productivity (Feng et al., 2002). Although AMF cannot fix atmospheric nitrogen, their interaction with fixing microorganisms can increase the fixation of this nutrient (Rajan et al., 2000).

The inoculation of S. rebaudiana with AMF has doubtlessly shown positive results, firstly because it leads to a greater biomass production - the commercial aspect of this crop. In this context, the inoculation of Glomus intraradices stimulated height, number of leaves, root length, and biomass production which are related to a higher chlorophyl content (Vafadar et al., 2014; Mandal et al., 2013). Parniske (2008) attributed this response to an improvement in the nutritional state of the plant, as a result of the extensive AMF hyphae network. This network covered a greater soil area, in order to absorb water and nutrients with low availability and mobility.

The AMF symbiosis can modify the quality of $S$. rebaudiana, by improving its growth habit. This situation was particularly observed when $25 \mathrm{mg}$ of phosphorous were applied 
as $\mathrm{P}_{2} \mathrm{O}_{5} \mathrm{~kg}^{-1}$ of soil, combined with AMF symbiosis (Tavarini et al., 2018), resulting in an increase of the SG yield. Nevertheless, further studies about the optimum phosphorous doses - based on the nutritional requirement of the plant - must be carried out, in order to avoid high concentrations and inhibiting AMF colonization.

On their part, Bidabadi and Masoumian (2008) proved that AMF could mitigate alterations caused by salinity stress, as a result of their positive impact on photosynthesis and the antioxidant defense system.

As essential components of soil biota, AMF also have "non-nutritional" effects: they prevent erosion, as a result of the production of a stable hydrophobic glycoprotein (glomalin), which joins the AMF hyphae, stabilizing soil aggregates and forming their longterm structure (Harrison, 1997). Arbuscular mycorrhizal symbiosis is also important for the phytoremediation of soils that have been polluted by heavy metals; the said metals are immobilized at the root and their translocation is reduced (Pawlowska et al., 2000).

\section{Mechanisms of arbuscular mycorrhizal fungi in the production of steviol glycosides}

One of the main mechanisms of symbiosis is its contribution to nutrient translocation (mainly phosphorous) which is essential for the steviol glycoside pathway (Tavarini et al., 2018). Although soils have very low concentrations of phosphorous, it is necessary for this process; additionally, as a result of its minimal mobility, it is not widely or easily available for the root system (Kapoor et al., 2007). Under these conditions, the AMF mycelial network is the most efficient way to increase its capture (Augé, 2004). A low phosphorous level in the soil solution means that there is also a low phospholipid level in the plant membrane, resulting in a greater root exudation that stimulates an AMF colonization (Bonfante et al., 2004).

Phosphorous is absorbed from the soil solution up to the plant as phosphate; the AMF's extraradical hyphae capture it quicker than diffusion; afterwards, the intraradical hyphae transport it to the cytoplasm. Alternatively, it is accumulated in vacuoles as polyphosphate granules; subsequently, it is sent through the hyphal lumen by cytoplasmic currents towards the arbusculae, where the polyphosphate is hydrolyzed and the phosphorous ion is transferred to the cell (Harrison, 1997).

On its turn, the phosphorous translocation mechanism improves the nitrogen, potassium, magnesium, and zinc assimilation (Jefferies et al., 2003), incorporating an optimal nutritional state that results in the production of biomass and the concentration of steviol glycosides in the leaves.

Steviol glycosides belong to the secondary metabolites that the plant produces. During the last decade, there has been relatively little information about the AMF-induced increases in the secondary metabolite production of $S$. rebaudiana. According to Mandal et al. (2013), this situation is the result of the lack of in-depth studies about the effect of inoculating tropical vegetables with AMF; other studies mainly focus in the AMF-driven production of secondary metabolites in medicinal herbs (Zubek et al., 2012). However, despite the growing evidence that AMF favor SG concentration, there is relatively little information about the mechanisms that are potentially involved in this increase. 
Glearly, the SG biosynthesis is largely dependent on the carbon's primary metabolism and the energy supplies that the plant can process. In this regard, the AMF-plant symbiosis improves photosynthesis through morphological (e.g., increase in leaf area) and physiological (e.g., regulation of stomatal conductance and chlorophyl concentration) adaptations (Turgeman et al., 2011) —which increases the plants carbohydrate content. SG biosynthesis takes place in the leaves and consists of three stages (Brandle et al., 1998): 1) the 2-G-methyl-D-erythritol-4-phosphate pathway (MEP) (Wanke et al., 2001) which leads to the conversion of pyruvate and glyceraldehyde-3-phosphate into kaurene; 2) the conversion of kaurene into steviol; and 3) the transformation of steviol into stevioside and rebaudioside-A by different glycosyltransferases (Brandle and Telmer, 2007).

A greater carbohydrate concentration increases gene transcription through the MEP pathway (Hsieh and Goodman, 2005); therefore, the AMF-plant symbiosis increases the expression of essential genes for SG biosynthesis (Mandal et al., 2015). In comparison with non-inoculated plants, the transcription levels of 1-deoxy-D-xylulose-5-phosphate synthase (DXS), 1-deoxy-D-xylulose-5-phosphate reductoisomerase (DXR), and 2-C-methyl-Derythritol-2,4-cyclodiphosphate synthase (MDS) increased 1.7-1.8 times respectively in the MEP pathway. In the second stage, the transcription levels of the five genes involved (GGDPS, CPPS, KS, KO, and KAH) increased 1.4-6.5 times when mycorrhization was involved; in the third stage, glycotransferases (UGT) underwent a positive regulation, guaranteeing a greater SG concentration (Guleria et al., 2014).

\section{Limitations on the use of arbuscular mycorrhizal fungi}

Biotic and abiotic factors can limit the use of AMF in the field, as well as the diversity and natural structure of the communities in the soil (Kernaghan, 2005). Plant species also determine AMF communities, based on the presymbiosis search compounds oozed by the roots to identify their preferred symbiont (Arnaut et al., 1996).

Despite the scarce evidence, other soil microorganism populations can establish a synergy with the AMF, while others can inhibit spore germination and colonization (Barea et al., 2002). Therefore, rhizosphere-associated microbiota has a positive or negative influence on AMF development (Gange, 2000).

Likewise, the soil's natural conditions - moisture, temperature, structure, and nutrient availability - also control AMF communities, colonization, and actions. Sometimes, these conditions are the consequence of agricultural practices (Jansa et al., 2003).

Soil can contribute to AMF development at one point and hinder it later on; it can directly or indirectly limit the effects of symbiosis on AMF communities or their host plants, respectively (Augé, 2000). Neither moisture deficit (Miller, 2000), nor temperature (Matsubara and Harada, 1996) have an impact on colonization, although they can reduce spore production.

Some agricultural practices —including fertilizer doses application, inadequate crop rotation, tilling, and the use of lime - impact mycorrhizal colonization levels (Entry et al., 2002). Some fertilization levels of phosphorous inhibit AMF efficiency in soy crops (Ezawa and Yoshida, 2002). Although AMF can survive in soils that have been highly polluted by heavy metals, such conditions diminish spore germination and colonization. 
Arbuscular mycorrhizal symbiosis is a microbiological tool that can be used as a sustainable fertilization alternative to produce Stevia rebaudiana; it provides benefits that influence the improvement of biomass yield and glycoside concentration. The combination of mutual benefit mechanisms (e.g., phosphorous translocation) makes the AMF and $S$. rebaudiana suitable symbionts: the plant species obtains enough phosphorous and other nutrients to improve its productivity and to concentrate its active ingredient (SG), while the AMF obtains the carbon it needs for its development.

\section{CONGLUSIONS}

Market demands require a sustainable production of $S$. rebaudiana; therefore, AMF must be taken into consideration as core elements of the cultivation and must be included in agronomy management plans. Mycorrhizae are a fundamental resource in soil structure and consequently for sustainability maintenance. Biotic or abiotic factors can threaten the communities, which must be incorporated into production plots.

\section{ACKNOWLEDGMENTS}

The authors would like to thank the Instituto Nacional de Investigaciones Forestales, Agrícolas y Pecuarias (INIFAP) for funding the Technology Research and Transference Project for the Use of Biofertilizers and Organic Manure in Agriculture No. 13451632421. The first author would like to thank the Consejo Nacional de Ciencia y Tecnología (CONACyT) for the postgraduate scholarship he was awarded. The authors would also like to thank the Posgrado en Agricultura Tropical Sustentable, Instituto Tecnológico de Conkal, Tecnológico Nacional de México, for their support for this research.

\section{REFERENGES}

Augé, R.M. (2000). Stomatal Behavior of Arbuscular Mycorrhizal Plants. In: Kapulnik Y., Douds D.D. (eds) Arbuscular Mycorrhizas: Physiology and Function. Springer, Dordrecht. https://doi.org/10.1007/97894-017-0776-3_10

Augé, R.M. (2004). Arbuscular mycorrhizae and soil/plant water relations. Canadian Journal of Soil Science 84 (4): 373-381. https://doi.org/10.4141/S04-002

Amekawa, Y. (2009). Reflections on the growing influence of good agricultural practices in the global south. Journal of Agricultural and Environmental Ethics 22 (6): 531-557. https://doi.org/bm4wg4

Arnaud, M., Hamel, C., Vimard, B., Caron, M., Fortin, J. A. (1996). Enhanced hyphal growth and spore production of the arbuscular mycorrhizal fungus Glomus intraradices in an in vitro system in the absence of host roots. Mycological research 100 (3): 328-332. https://doi.org/cztv3w

Akiyama, K. (2005). Plant sesquiterpenes induce hyphal branching in arbuscular mycorrhizal fungi. Nature 435: 824-827. https://doi.org/10.1038/nature03608

Barea, J. M., Toro, M., Orozco, M. O., Campos, E., Azcón, R. (2002). The application of isotopic (32 P and $15 \mathrm{~N}$ ) dilution techniques to evaluate the interactive effect of phosphate-solubilizing rhizobacteria, mycorrhizal fungi and Rhizobium to improve the agronomic efficiency of rock phosphate for legume crops. Nutrient Cycling in Agroecosystems 63 (1): 35-42. https://doi.org/bt9tbw

Bidabadi, S. S. and Masoumian, M. (2018). Arbuscular mycorrhizal symbiosis improves growth and antioxidative response of Stevia rebaudiana (Bert.) under salt stress. Trends in Horticulture 1 (3):1-8. https:// doi.org/f77p

Bonfante, P., Genre, A., and Bianciotto, V. (2004). The colonisation strategies of arbuscular mycorrhizal fungi: an overview of their cellular interactions with plants and bacteria. In: Avance en el conocimiento de la biología de las micorrizas. J.T. Frías-Hernández, V. Olalde-Portugal, R. Ferrera-Cerrato (Eds). Primera Edición. Universidad de Guanajuato. Guanajuato, México, Pp 19-28.

Bonfante, P. and Genre, A. (2008). Plants and arbuscular mycorrhizal fungi: an evolutionary developmental perspective. Trends in Plant Science 13 (9): 492-498. https://doi.org/cg8hs5 
Brandle, J. E., Starratt, A. N., Gijzen, M. (1998). Stevia rebaudiana: Its agricultural, biological, and chemical properties. Canadian Journal of plant science 78 (4): 527-536. https://doi.org/cn6qdn

Brandle,J. E. and Telmer, P. G. (2007). Steviol glycoside biosynthesis. Phytochemistry 68(14): 1855-1863. https:// doi.org/d2bt6g

Brundrett, M. (2004). Diversity and classification of mycorrhizal associations. Biological reviewes 79 (3): 473-495. https://doi.org/bt6pwk

Camarena-Gutiérrez, G. (2012). Interacción planta-hongos micorrízicos arbusculares. Revista Chapingo serie ciencias forestales y del ambiente 18 (3): 409-421. https://doi.org/f77d

Entry, J. A., Rygiewicz, P. T., Watrud, L. S., Donnelly, P. K. (2002). Influence of adverse soil conditions on the formation and function of arbuscular mycorrhizas. Advances in Environmental Research 7 (1): 123-138. https://doi.org/ds9xtf

Ezawa, T., Yamamoto, K., Yoshida, S. (2002). Enhancement of the effectiveness of indigenous arbuscular mycorrhizal fungi by inorganic soil amendments. Soil Science and Plant Nutrition 48 (6): 897-900. https:// doi.org/bdcrwz

Feng, G., Zhang, F., Li, X., Tian, C., Tang, C., Rengel, Z. (2002). Improved tolerance of maize plants to salt stress by arbuscular mycorrhiza is related to higher accumulation of soluble sugars in roots. Mycorrhiza 12 (4): 185-190. https://doi.org/bw288z

Gange, A. (2000). Arbuscular mycorrhizal fungi, Collembola and plant growth. Trends in Ecology \& Evolution 15 (9): 369-372. https://doi.org/fh437d

Gardana, C., Scaglianti, M., Simonetti, P. (2010). Evaluation of steviol and its glycosides in Stevia rebaudiana leaves and commercial sweetener by ultra-high-performance liquid chromatography mass spectrometry. Journal of Chromatography A 1217: 1463-1470. https://doi.org/bf6f8h

Giovannini, L., Palla, M., Agnolucci, M., Avio, L., Sbrana, C., Turrini, A., Giovannetti, M. (2020). Arbuscular mycorrhizal fungi and associated microbiota as plant biostimulants: research strategies for the selection of the best performing inocula. Agronomy 10 (1): 106. https://doi.org/f78b

Guleria, P., Masand, S., Yadav, S. K. (2014). Overexpression of SrUGT85C2 from Stevia reduced growth and yield of transgenic Arabidopsis by influencing plastidial MEP pathway. Gene 539 (2): 250-257. https:// doi.org/f5wfr5

Harrison, M. J. (1997). The arbuscular mycorrhizal symbiosis. In Plant-microbe interactions (pp. 1-34). Springer, Boston, MA. https://doi.org/dsz2c9

Hsieh, M. H. and Goodman, H. M. (2005). The Arabidopsis IspH homolog is involved in the plastid nonmevalonate pathway of isoprenoid biosynthesis. Plant physiology 138 (2): 641-653. https://doi.org/ cmxcc7

Jansa, J., Mozafar, A., Kuhn, G., Anken, T., Ruh, R., Sanders, I. R., Frossard, E. (2003). Soil tillage affects the community structure of mycorrhizal fungi in maize roots. Ecological Applications 13 (4): 1164-1176. https://doi.org/fb9fqs

Jefferies, P., Gianinazzi, S., Perotto, S., Turnau, K., Barea, J. M. (2003). The contributionof arbuscular mycorrhizal fungi in sustainable maintenance of plant health andsoil fertility. Biology and Fertility of Soils 37: 1-16. https://doi.org/dhpj87

Kapoor, R., Chaudhary, V., Bhatnagar, A. K. (2007). Effects of arbuscular mycorrhiza and phosphorus application on artemisinin concentration in Artemisia annua L. Mycorrhiza 17: 581-587. https://doi.org/ c72×36

Kernaghan, G. (2005). Mycorrhizal diversity: cause and effect?. Pedobiologia 49(6): 511-520. https://doi.org/ bj75v9

Mandal, S., Evelin, H., Giri, B., Singh, V. P., Kapoor, R. (2013). Arbuscular mycorrhiza enhances the production of stevioside and rebaudioside-A in Stevia rebaudiana via nutritional and non-nutritional mechanisms. Applied Soil Ecology 72: 187-194. https://doi.org/f77g

Mandal, S., Upadhyay, S., Singh, V. P., Kapoor, R. (2015). Enhanced production of steviol glycosides in mycorrhizal plants: a concerted effect of arbuscular mycorrhizal symbiosis on transcription of biosynthetic genes. Plant Physiology and Biochemistry 89: 100-106. https://doi.org/f67g9v

Matsubara, Y. I., and Harada, T. (1996). Effect of constant and diurnally fluctuating temperatures on arbuscular mycorrhizal fungus infection and the growth of infected asparagus (Asparagus officinalis L.) seedlings. Journal of the Japanese Society for Horticultural Science 65 (3): 565-570. https://doi.org/bh8cv4

Miransari, M., Bahrami, H.A., Rejali, F., Malakouti, M.J., Torabi, H. (2007). Using arbuscular mycorrhiza to reduce the stressful effects of soil compaction on corn (Zea mays L.) growth. Soil Biology and Biochemistry 39: 2014-2026. https://doi.org/ffs4ww

Miller, S. P. (2000). Arbuscular mycorrhizal colonization of semi aquatic grasses along a wide hydrologic gradient. New Phytologist 145 (1): 145-155. https://doi.org/c59vrr 
Mogra, R. and Dashora, V. (2009). Exploring the use of Stevia rebaudiana as a sweetener in comparison with other sweeteners. Journal of Human Ecology 25 (2): 117-120. https://doi.org/f77v

Pawlowska, T. E., Chaney, R. L., Chin, M., Charvat, I. (2000). Effects of metal phytoextraction practices on the indigenous community of arbuscular mycorrhizal fungi at a metal-contaminated landfill. Applied and Environmental microbiology 66 (6): 2526-2530. https://doi.org/cd3xdw

Parniske, M. (2008). Arbuscular mycorrhiza: the mother of plant root endosymbioses. Nature Reviewes Microbiology 6: 763-775. https://doi.org/btrpt2

Rajan, S. K., Reddy, B. J. D., Bagyaraj, D. J. (2000). Screening of arbuscular mycorrhizal fungi for their symbiotic efficiency with Tectona grandis. Forest ecology and management 126 (2): 91-95. https://doi.org/ cqr3x6

Ramesh, K., Singh, V., Megeji, N. W. (2006). Cultivation of stevia [Stevia rebaudiana (Bert.) Bertoni]: A comprehensive review. Advances in Agronomy 89: 137-177. https://doi.org/dhw5v5

Rillig, M. C. (2004). Arbuscular mycorrhizae and terrestrial ecosystem processes. Ecological Letters 7: 740-754. https://doi.org/b8x2qd

Rich, M. K., Schorderet, M., Reinhardt, D. (2014). The role of the cell wall compartment in mutualistic symbioses of plants. Frontiers in Plant Science 5: 238. https://doi.org/f6bjj9

Sarmiento-López, L. G., López-Meyer, M., Sepúlveda-Jiménez, G., Cárdenas, L., Rodríguez-Monroy, M. (2021). Arbuscular mycorrhizal symbiosis in Stevia rebaudiana increases trichome development, flavonoid and phenolic compound accumulation. Biocatalysis and Agricultural Biotechnology 31: 101889. https://doi.org/f77r

Simon L., Bousquet J., Levesque R. G., Lalonde M. (1993). Origin and diversification of endomycorrhizal fungi and coincidence with vascular land plants. Nature 363: 67-69. https://doi.org/d5p52s

Schüßler, A., Schwarzott., D, Walker, C. (2001). A new fungal phylum, the Glomeromycota: phylogeny and evolution. Mycological Research 105: 1413-1421. https://doi.org/c86djq

Tavarini, S., Angelini, L. G. (2013). Stevia rebaudiana Bertoni as a source of bioactive compounds: the effect of harvest time, experimental site and crop age on steviol glycoside content and antioxidant properties. Journal of Science of Food and Agriculture 93 (9): 2121-2129. https://doi.org/f4z9zq

Tavarini, S., Sgherri, C., Ranieri, A.M., Angelini, L.G. (2015). Effect of nitrogen fertilization and harvest time on steviol glycosides, flavonoid composition, and antioxidant properties in Stevia rebaudiana Bertoni. Journal of Agricultural and Food Chemistry 63 (31): 7041-7050. https://doi.org/f7nwcd

Tavarini, S., Passera, B., Martini, A., Avio, L., Sbrana, C., Giovannetti, M., Angelini, L. G. (2018). Plant growth, steviol glycosides and nutrient uptake as affected by arbuscular mycorrhizal fungi and phosphorous fertilization in Stevia rebaudiana Bert. Industrial Crops and Products 111: 899-907. https:// doi.org/f7nwcd

Turgeman, T., Asher, J. B., Roth-Bejerano, N., Kagan-Zur, V., Kapulnik, Y., Sitrit, Y. (2011). Mycorrhizal association between the desert truffle Terfezia boudieri and Helianthemum sessiliflorum alters plant physiology and fitness to arid conditions. Mycorrhiza 21 (7): 623-630. https://doi.org/d22r45

Vafadar, F., Amooaghaie, R., Otroshy, M. (2014). Effects of plant-growth-promoting rhizobacteria and arbuscular mycorrhizal fungus on plant growth, stevioside, NPK, and chlorophyll content of Stevia rebaudiana. Journal of Plant Interactions 9 (1): 128-136. https://doi.org/f77m

Vierheilig, H. (2004). Regulatory mechanisms during the plant arbuscular mycorrhizal fungus interaction. Canadian Journal of Botany 82 (8): 1166-1176. https://doi.org/dkwg87

Wanke, M., Skorupinska-Tudek, K., Swiezewska, E. (2001). Isoprenoid biosynthesis via 1-deoxy D-xylulose 5-phosphate/2-C-methyl-D-erythritol 4-phosphate (DOXP/MEP) pathway. Acta Biochimica Polonica 48 (3): 663-672. https://doi.org/f77n

Zubek, S., Mielcarek, S., Turnau, K. (2012). Hypericin and pseudohypericin concentrations of a valuable medicinal plant Hypericum perforatum L. are enhanced by arbuscular mycorrhizal fungi. Mycorrhiza 22 (2): 149-156. https://doi.org/c537f8

Young, K.E., Zwank, P.J., Valdez, R., Dye, J.L., \& Tarango, L.A. (1997). Diet of Mexican spotted owls in Chihuahua and Aguascalientes, Mexico. Journal of Raptor Research 31 (4): 376-380 